\title{
ANALISIS STUDI KELAYAKAN PADA USAHA SUP BUAH
}

\section{Dewi Rahmawati}

\author{
Jurusan Teknik Industri, Institut Teknologi Garut, Jl. Mayor Syamsu No.1, Jayaraga, Garut, \\ Jawa Barat 44151, Indonesia \\ Email: dewi_rahmawati@itg.ac.id
}

\begin{abstract}
ABSTRAK
Peningkatan konsumsi buah-buahan secara nasional menciptakan peluang usaha dalam bidang tersebut, salah satunya usaha sup buah. Untuk menciptakan usaha sup buah yang efektif dan efisien diperlukan pengamatan kelayakan pada usaha. Hal ini bertujuan untuk mengetahui kelayakan usaha sup buah dan meminimasi tingkat ketidakpastian dalam menjalankannya dan mengurangi ketakutan pengusaha baru dalam menjalankan usaha. Metode penelitian ini menggunakan pendekatan mixed methods, dimana tahap awal menggunakan metode kuantitatif dengan studi kelayakan dan analisis sensitifitas yang berguna untuk mengetahui kelayakan usaha dan meminimasi ketidakpastian kedepannya serta metode kualitatif dengan analisis SWOT yang berguna untuk mengetahui keadaan yang mungkin akan terjadi pada usaha sup buah. Hasil penelitian menunjukan dengan adanya pengaruh perubahan variabel seperti kenaikan bahan baku sebesar 30\% dan penurunan sebesar 5\% dibandingkan dengan kondisi normal, tetap menunjukan bahwa usaha sup buah masih layak untuk dijalankan dengan memperhatikan faktor kekuatan, kelemahan, peluang dan ancaman dalam menjalankan usaha untuk lima tahun ke depan, sehingga perencanaan menjadi lebih efektif serta efisien.
\end{abstract}

Kata Kunci: Analisis Sensitivitas, Analisis SWOT, Studi Kelayakan Usaha

\begin{abstract}
Increasing consumption of fruits nationally creates business opportunities in this field, one of which is the fruit soup business. To make an effective and efficient fruit soup business, and necessary to observe its study feasibility. The aims are to determine the feasibility of a fruit soup business and minimize the level of uncertainty in running it and reduce the fear of new entrepreneurs in running a business. This research method uses a mixed-methods approach. The initial stage uses quantitative methods with feasibility studies and sensitivity analyses that are useful for determining business viability and minimizing future uncertainties. Qualitative methods with SWOT analysis are to help know conditions that might occur in the fruit soup business. The result showed changes in variables such as an increase in raw materials by $30 \%$ and a decrease of $5 \%$ compared to customary conditions. It still showed that the fruit soup business is still
\end{abstract}


feasible to run by considering the strengths, weaknesses, opportunities, and threats in running a business for five years ahead so that planning becomes more effective and efficient.

Keywords: Feasibility Study, Sensitivity Analysis, SWOT Analysis

\section{PENDAHULUAN}

Buah-buahan merupakan sumber vitamin dan mineral yang diperlukan oleh tubuh. Konsumsi buah buahan mengalami kenaikan sebesar 0,44 persen secara nasional yang memberikan peluang bagi perusahaan untuk menjalankan suatu usaha di bidang produksi dan distribusi buah (Chatarine, 2012). Salah satu peluang usahanya yaitu usaha sup buah.

Untuk menjalankan sebuah usaha sup buah tersebut diperlukan perencanaan atau studi yang cukup baik, efektif, dan efisien seperti yang dijelaskan oleh (Saleh, 2020) bahwa studi yang dilakukan oleh pengusaha untuk memastikan penerapan rencana/ idenya dapat berjalan atau tidak yaitu menggunakan studi kelayakan. Hal ini bertujuan untuk mengetahui kelayakan usaha sup buah dan meminimasi tingkat ketidakpastian dalam menjalankannya dan untuk membantu mengurangi ketakutan pengusaha baru dalam menjalankan usaha. Studi kelayakan merupakan langkah awal, persiapan perusahaan dalam mengambarkan arus kas untuk meminimalkan risiko startup dengan menghitung dan menganalisis, sehingga mampu menciptakan perusahaan baru yang dapat menghasilkan output sesuai dengan keinginan pemiliknya (Kwarti et al., 2019; Sharfina et al., 2019; Zativita \& Chumaidiyah, 2019).
Penelitian ini dilakukan untuk mengetahui apakah usaha layak dijalankan dengan ditinjau dari aspek pasar, aspek teknis ataupun aspek keuangan. Aspek pasar digunakan untuk menentukan sasaran yang tersedia atau mengidentifikasi dimana produk akan dijual dan memperhatikan pesaing (Saleh, 2020). Untuk aspek teknis membantu melihat pengeluaran terjadi dalam 5 tahun ke depan dan aspek keuangan ditinjau menggunakan metode Payback Period (PP), Net Present Value (NPV), Internal Rate of Return (IRR) (Adikusuma \& Utami, 2018; Hutasoit et al., 2021; Kwarti et al., 2019; Nainggolan, 2020; Sutrisno, 2019; Wimartanti \& Sonny, 2021; Zativita \& Chumaidiyah, 2019). Pada setiap aspek akan ada resiko atau ancaman seperti kesalahan harga, keterbatasan modal, promosi, persaingan harga, kenaikan dan penurunan bahan baku. Oleh karena itu, dilakukan analisis sensitivitas untuk mengetahui kondisi bisnis jika terjadi perubahan yang tidak diinginkan (Nurazizah \& Chumaidiyah, 2020; Sutrisno, 2019; Zativita \& Chumaidiyah, 2019). Analisis Sensitivitas didefinisikan sebagai besaran relatif perubahan dalam satu atau lebih faktor yang akan mengambil keputusan di antara alternatif yang lebih kuat dengan perubahan faktor-faktor yang mempengaruhi usaha. Perubahan faktor tersebut akan mempengaruhi kekuatan (Strenght-S), kelemahan 
(Weakness-W), peluang (Opportunity $O)$ dan ancaman (Threats -T) dalam usaha atau disebut dengan strategi dalam analisis SWOT (Hatamilah, 2017; Wimartanti \& Sonny, 2021). Analisis SWOT dapat dilakukan untuk mengoptimalkan kerjasama, sehingga mampu memberikan peluang dalam berusaha dan menyediakan kebutuhan yang optimal serta m.eminimasi potensi ancaman dari usaha yang dijalankan (Adikusuma \& Utami, 2018; Nainggolan, 2020).

Berdasarkan hal tersebut, karena belum ada penelitian yang membahas strategi SWOT dengan analisis sensitivitas dalam menentukan studi kelayakan secara bersamaan untuk industri kuliner, maka tujuan penelitian yaitu menganalisis aspekaspek tersebut secara bersamaan. Hal ini dilakukan untuk mengetahui apakah usaha sup buah layak atau tidak untuk dijalankan dengan adanya perubahan pada beberapa faktor seperti lingkungan, bahan baku dan lainnya yang ditinjau kekuatan (Strenght-S), kelemahan (Weakness-W), peluang (Opportunity -O) dan ancaman (Threats $-T$ ) usaha tersebut. Jika hasil studi menunjukkan usaha tersebut layak, kemungkinan untuk keberhasilan proyek dan mencapai tujuan yang diinginkan jauh lebih besar (Saleh, 2020). Jika hasil studi menunjukkan usaha tersebut tidak layak, proyek akan dibatalkan sehingga mampu menghemat banyak uang, tenaga dan waktu (Saleh, 2020).

\section{METODE}

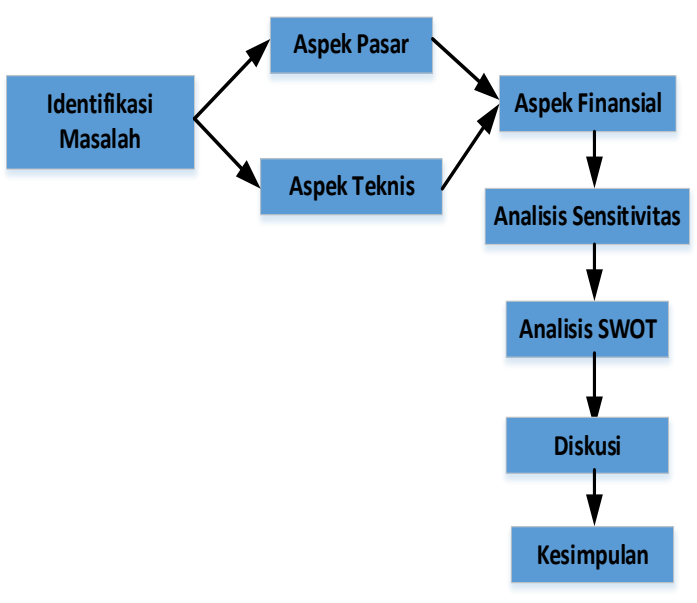

Gambar 1. Model Konseptual

Metode pada penelitian ini mengunakan metode mixed methods yaitu penggunaan metode kuantitatif pada tahap studi kelayakan dan analisis sensitifitas untuk mengetahui kelayakan usaha dan meminimasi ketidakpastian kedepannya serta metode kualitatif untuk analisis SWOT karena diperlukan pengujian melalui uji keabsahan data. Adapun tahap penelitian dimulai dengan mengidentifikasi dan merumuskan masalah, menentukan tujuan serta batasan masalah agar penelitian sesuai dengan ruang lingkup yang dibutuhkan (Zativita \& Chumaidiyah, 2019). Untuk model konseptual penelitian ini terlihat pada Gambar 1, dimana setiap aspek memiliki keterkaitan satu sama lain (Nurazizah \& Chumaidiyah, 2020). Proses pengamatan dimulai dengan mengidentifikasi masalah, analisis aspek pasar dan aspek teknis untuk menentukan kelayakan investasi, serta pengamatan lebih lanjut menggunakan analisis sensitivitas dan analisis SWOT. Identifikasi masalah dilakukan untuk mengetahui kendala 
apa yang mungkin akan terjadi. Analisis aspek pasar dilakukan untuk mengetahui peluang pasar terkait dengan perilaku konsumen mengenai penggunaan harga dan persaingan pasar, atau untuk mengetahui besarnya permintaan jumlah produk yang akan diproduksi dan memposisikan produk pada tempat yang dapat menghasilkan keuntungan (Zativita \& Chumaidiyah, 2019). Analisis selanjutnya adalah aspek teknis yang dilakukan untuk mengetahui jumlah pekerja, lokasi pabrik bisnis, dan kebutuhan pendanaan serta keluaran dari aspek teknis adalah biaya investasi awal dan biaya operasional yang akan digunakan dalam analisis aspek keuangan (Nurazizah \& Chumaidiyah, 2020; Zativita \& Chumaidiyah, 2019).

Proses identifikasi, analisis aspek pasar dan teknikal yang telah dilakukan akan berpengaruh dalam menentukan studi kelayakan untuk mengetahui apakah usaha yang direncanakan layak atau tidak untuk dijalankan. Pengamatan lebih lanjut dengan analisis sensitivitas untuk mengetahui dampak dari adanya perubahan seperti bahan baku dan lingkungan apakah akan mempengaruhi atau tidak terhadap kelayakan pada usaha tersebut (Nurazizah \& Chumaidiyah, 2020; Zativita \& Chumaidiyah, 2019). Selain itu, setelah mengetahui usaha tersebut layak atau tidak untuk dijalankan dengan adanya variabel perubahan, selanjutnya dilakukan analisis SWOT yang ditinjau dari 4 hal yaitu Strengths, Weaknesses, Opportunities, dan Threats untuk mengoptimalkan kinerja (Nainggolan, 2020).

\section{HASIL DAN PEMBAHASAN}

Hasil dan analisis pada penelitian ini adalah melengkapi penelitian dari (Hutasoit et al., 2021; Kwarti et al., 2019; Nainggolan, 2020; Zativita \& Chumaidiyah, 2019) yang mengukur kelayakan dari investasinya agar mengetahui apakah usaha tersebut layak atau tidak untuk di jalankan khususnya pada usaha sup buah yang akan dijalankan pada penelitian ini. Berdasarkan hasil pengamatan dengan mengedepankan kualitas pada bahan baku untuk 5 tahun kedepan pada kondisi normal menunjukan bahwa NPV menghasilkan nilai sebesar Rp 119.255.875 >0 Nilai IRR yang didapat sebesar $28.51 \%>$ MARR $10.25 \%$ dan usaha nilai PP selama 3 tahun 1 (satu) bulan 20 hari. Hal tersebut menunjukan bahwa usaha sup buah layak untuk dijalankan karena telah memenuhi ketentuannya.

\begin{tabular}{cll}
\multicolumn{3}{c}{ Tabel 1. NPV dan nilai IRR } \\
\hline Tahun & Net Cash Flow & Present Value \\
\hline 0 & -161.760 .000 & -161.760 .000 \\
1 & 13.785 .600 & 12.503 .946 \\
2 & 45.540 .480 & 37.466 .266 \\
3 & 80.651 .424 & 60.183 .334 \\
4 & 115.717 .914 & 78.322 .439 \\
5 & 150.737 .730 & 92.539 .890 \\
\hline & NPV & $119.255 .875 \quad>0$ \\
& & Usaha Layak \\
\hline & IRR & 28,51\%>MARR \\
& & Usaha Layak \\
\hline
\end{tabular}

Sumber: Data primer diolah (2021)

Apabila ditinjau dari pendapat (Mandasari et al., 2019; Nurazizah \& Chumaidiyah, 2020; Zativita \& Chumaidiyah, 2019) menyatakan bahwa dalam studi kelayakan ada faktor atau variabel lain yang akan berubah mempengaruhi usaha, sehingga diperlukan analisis 
sensitivitas dan kemudian diuji kembali apakah usahanya akan tetap layak atau tidak apabila terjadi perubahan dalam variabel pendukung usaha. Pada penelitian ini ada beberapa variabel yang berpotensi akan berubah setiap tahunya seperti halnya kenaikan dan penurunan bahan baku, walaupun persentasi penurunan tidak akan tinggi seperti kenaikan bahan baku. Oleh karena itu, dilakukan pengujian dengan kenaikan bahan baku untuk 5 tahun kedepan sebesar 30\% dan penurunan bahan baku sebesar 5\% dengan harga jual sup buah Rp 15.000 per buah dan kapasitas produksi 12.000 - 24.000 per tahun. Hasil dari pengujiannnya menunjukan jika kenaikan bahan baku $30 \%$, maka NPV menjadi Rp 31.791.138 $>0$ dan lebih kecil dari kondisi normal, IRR 15,53\%>MARR 10,25\%, PP 4 tahun 1 bulan 17 hari, adapun bila bahan baku menurun sampai 5\%, maka nilai dari usaha tersebut menjadi NPV Rp 145.171.354 $>0$ dan lebih besar dari kondisi normal, IRR 32.00\%>MARR 10,25\%, dan PP 3 tahun 1 bulan 13 hari. Faktor pembanding tersebut menunjukan bahwa, kenaikan atau penurunan bahan baku tetap membuat usaha tersebut layak untuk dijalankan hanya saja terdapat perbedaan hasil dan kesamaan pada nilai payback pariod.

Menurut Nainggola setelah mengetahui studi kelayakan diperlukan analisis SWOT yang meliputi Strength, Weaknesses, Opportunities, dan Threats dalam membuat usaha agar proses menjadi efisien dan efektif. Semua hal tersebut dilakukan agar UMKM mampu untuk bertahan, melawan krisis nasional. Walaupun Kompetensi kewirausahaan pelaku UMKM masih menjadi salah satu tantangan bagi Indonesia (Dika et al., 2021; Nainggolan, 2020; Prakasa \& Putri, 2020).

Tabel 2. SWOT

\begin{tabular}{|c|c|c|}
\hline & Kekuatan (Strenght-S) & Kelemahan (Weakness-W) \\
\hline & $\begin{array}{l}\text { 1. Bahan baku } \\
\text { berkualitas } \\
\text { 2. Bahan baku mudah } \\
\text { didapat } \\
\text { 3. Harga terjangkau }\end{array}$ & $\begin{array}{l}\text { 1. Tidak tahan lama atau } \\
\text { mudah busuk } \\
\text { 2. Memerlukan berbagai } \\
\text { macam bahan baku } \\
\text { 3. Modal yang dibutuhkan } \\
\text { tinggi }\end{array}$ \\
\hline Peluang (Opportunity -O) & Strategi (S-O) & Strategi (W-O) \\
\hline $\begin{array}{l}\text { 1. Peminat banyak } \\
\text { 2. Produk sudah dikenal } \\
\text { masyarakat } \\
\text { 3. Pemasaran dapat } \\
\text { dilakukan secara offline } \\
\text { atau online }\end{array}$ & 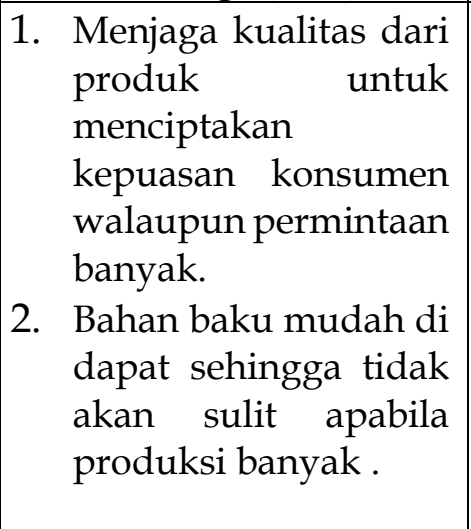 & $\begin{array}{l}\text { 1. Melakukan promosi } \\
\text { untuk menarik kembali } \\
\text { perhatian masyarakat } \\
\text { dan mempercepat proses } \\
\text { penjualan. } \\
\text { 2. Menggunakan berbagai } \\
\text { macam bahan baku akan } \\
\text { membuat menarik } \\
\text { perhatian konsumen, } \\
\text { tetapi akan berpengaruh } \\
\text { terhadap harga produk. }\end{array}$ \\
\hline
\end{tabular}




\begin{tabular}{|c|c|c|}
\hline & $\begin{array}{l}\text { 3. Pembelian dapat } \\
\text { dilakukan secara } \\
\text { offline atau online } \\
\text { dengan harga yang } \\
\text { relatif terjangkau. }\end{array}$ & $\begin{array}{l}\text { 3. Peluang bisnis baik } \\
\text { tetapi modal terbatas. }\end{array}$ \\
\hline Ancaman (Threats $-T)$ & Strategi (S-T) & Strategi (W-T) \\
\hline $\begin{array}{l}\text { 1. Harga bahan baku } \\
\text { dapat lebih tinggi dari } \\
\text { biasanya } \\
\text { 2. Produk banyak } \\
\text { pesaing } \\
\text { 3. Jika hujan peminat } \\
\text { berkurang }\end{array}$ & \begin{tabular}{|lr} 
1. & $\begin{array}{l}\text { Bahan baku } \\
\text { berkualitas dan }\end{array}$ \\
mudah di dapat, \\
tetapi harga bahan \\
baku mahal. \\
2. \\
Bahan dan cara \\
mudah untuk \\
dilakukan sehingga \\
banyak pesaing \\
3. $\begin{array}{l}\text { Harga terjangkau } \\
\text { apabila kondisi }\end{array}$ \\
hujan dan promosi \\
yang kurang akan \\
berpengaruh pada \\
target penjualan.
\end{tabular} & $\begin{array}{l}\text { 1. } \begin{array}{l}\text { Banyak pesaing dengan } \\
\text { produk dan harga }\end{array} \\
\text { variatif. } \\
\text { 2. Melakukan penekanan } \\
\text { kebutuhan produksi } \\
\text { agar harga produk tidak } \\
\text { jauh dari harga pasar. } \\
\text { 3. Memaksimalkan } \\
\text { promosi dengan modal } \\
\text { yang ada. }\end{array}$ \\
\hline
\end{tabular}

Berdasarkan pemaparan diatas, perlu diperhatikan keempat aspek utama. Aspek tersebut diantaranya kekuatan (Strenght-S), kelemahan (Weakness-W), peluang (Opportunity $O)$ dan ancaman (Threats -T) ketika menjalankan usaha sup buah untuk kedepannya. Hal ini perlu diperhatikan karena analisis SWOT membantu untuk membentuk rekomendasi berupa pilihan strategi generic (Susantiningrum et al., 2020).

\section{KESIMPULAN}

Proses analisis yang telah dilakukan pada usaha sup buah ini menunjukan bahwa nilai NPV Rp 119.255.875 > 0, Nilai IRR $28.51 \%>$ dan PP 3 tahun 1 (satu) bulan 20 hari menunjukan usaha tersebut layak. Selain itu, untuk lima tahun kedepan walaupun adanya perubahan pada variabel bahan baku usaha sup buah masih layak untuk dijalankan. Analisis yang dilakukan tersebut menunjukan bahwa metode yang digunakan memiliki hubungan yang saling keterkaitan satu sama lain apabila ditinjau dari aspek kelayakan dan aspek Strength, Weaknesses, Opportunities, dan Threats dalam membuat usaha agar proses menjadi efisien dan efektif. Oleh karena itu, untuk penelitian lebih lanjut dapat mengembangkan kelayakan usaha dengan memperhatikan variabel perubahan lainnya yang akan terjadi kedepannya dengan memperhatikan aspek pemasaran secara digital.

\section{DAFTAR PUSTAKA}

Adikusuma, R. F., \& Utami, C. W. (2018). Feasibility Study Of Business Development Of Beef 
Cattle Breeding In Ud. Pakindo. The Fifth International Conference On Enterpreneurship.

Chatarine, V. A. (2012). Strategi Pengembangan Bisnis Buah Semangka Pada Cv Salim Abadi, Kabupaten Lampung Tengah, Provinsi Lampung. Ipb University.

Dika, C. W., Rita, M. R., \& Sakti, I. M. (2021). Financial Bootstrapping Dan Kinerja Umkm: Peran Moderasi Literasi Keuangan. Jurnal Kewirausahaan Dan Bisnis, 26(1), 37-44. Https://Doi.Org/10.20961/Jkb.V 26i1.44726.G32036

Hatamilah, S. (2017). Application And Choosing Strategies Using Swot Analysis And Qspm Matrix: A Case Study Of Al-Mursalat Mobile Phones Complex. International Journal of Advanced Production And Industrial Engineering, 2(1), 32-40.

Hutasoit, G. M., Chumaidiyah, E., \& Praptono, B. (2021). Feasibility Analysis Of Culinary Business Cafe Nusantara Development In The Central Of Jakarta. In International Conference On Rural Development And Entrepreneurship 2019 (Vol. 5, Issue 1).

Kwarti, C., Marsiwi, K., Yanuar, T., Syah, R., Pusaka, S., \& Indradewa, R. (2019). Investment Feasibility Analysis In Financial Aspects Of Startup Business In Lifestyle Combining Barbershop And Coffee Shop Over Pt. Jeeva Work Corporation. Journal of Multidisciplinary Academic, 3(4), 97-100.
Mandasari, D. J., Widodo, J., \& Djaja, S. (2019). Strategi Pemasaran Usaha Mikro, Kecil Dan Menengah (Umkm) Batik Magenda Tamanan Kabupaten Bondowoso. Jurnal Pendidikan Ekonomi: Jurnal Ilmiah Ilmu Pendidikan, Ilmu Ekonomi Dan Ilmu Sosial, 13(1), 123-128.

Https:// Doi.Org/10.19184/Jpe.V $13 \mathrm{i} 1.10432$

Nainggolan, O. V. B. (2020). Feasibility Analysis Of Small And Medium Enterprises Of Shoes And Slippers In Bogor. Conference On Business, Management, And Entrepreneurship (Gcbme 2018), 166-169.

Https://Doi.Org/10.2991/Aebm r.K.200131.036

Nurazizah, F., \& Chumaidiyah, E. (2020). Business Design And Feasibility Of Puru Kambera Muslim Fashion Offline Store Establishment. Iop Conference Series: Materials Science And Engineering, 1003(1), 012038. Https://Doi.Org/10.1088/1757899x/1003/1/012038

Prakasa, Y., \& Putri, Y. R. (2020). Iklim Kewirausahaan Dan Kompetensi Kewirausahaan: Upaya Untuk Meningkatkan Kinerja Usaha (Studi Pada Umkm Batik Tulis Bayat, Klaten). Jurnal Kewirausahaan Dan Bisnis, 25(2), 104-118.

Https:// Doi.Org/10.20961/Jkb.V 25i2.45166.G29537

Saleh, S. (2020). Feasibility Study For A Startup Company. Turku University Of Applied Sciences.

Sharfina, N., Yuniaristanto, \& Zakaria, 
R. (2019). Business Development On Bukasuara Startup With Startup Evolution Curve Methods. International Conference On Engineering And Management In Industrial System (Icoemis 2019) Business, 184-191. Https:/ /Doi.Org/10.2991/Icoem is- 19.2019 .26

Susantiningrum, S., Triharyanto, E., \& Hantari, D. (2020). Analisis Swot Penelitian Dan Pengabdian Masyarakat Pusat Pengembangan Kewirausahaan. Jurnal Kewirausahaan Dan Bisnis, 25(2), 96-103.

Https:/ /Doi.Org/10.20961/Jkb.V 25i2.45511.G29533

Sutrisno, S. (2019). The Feasibility Of Staple Food Business And Its Implication On Regional Food Supply Chain Development. Journal of Socioeconomics And Development, 2(1), 54-60. Https:/ / Doi.Org/10.31328/Jsed. V2i1.956

Wimartanti, S. N., \& Sonny, S. (2021). Business Feasibility Study Of Healthy Food Restaurant In Bekasi. Proceeding Of International Conference On Family Business And Entrepreneurship, 0(0).

Zativita, F. I., \& Chumaidiyah, E. (2019). Feasibility Analysis Of Rumah Tempe Zanada Establishment In Bandung Using Net Present Value, Internal Rate Of Return, And Payback Period. Iop Conference Series: Materials Science And Engineering, 505(1), 012007.

Https:/ / Doi.Org/10.1088/1757899x/505/1/012007 